\title{
PerCursos
}

\section{A reiteração do assalto ao paraíso: pesca, pescadores e marisqueiras de Arembepe, Bahia}

\begin{abstract}
Resumo
O presente artigo tem por objetivo analisar a tradição da pesca na comunidade pesqueira de Arempebe (BA) e, para isso, lançamos o olhar investigativo sobre a obra Assault on Paradise, do antropólogo americano Conrad Kottak que, na década de 1960, adotou essa localidade como seu campo de estudo. Trata-se de uma pesquisa de natureza etnobiológica e de abordagem qualitativa. Foram entrevistados 31 pescadores e marisqueiras com idade igual e maior a 40 anos e vinculados à colônia de pesca Z-14. $\mathrm{Na}$ comunidade pesqueira de Arembepe, o método de pesca é artesanal e a tradição mantém-se ao longo das gerações. A preservação dos traços culturais é presente na comunidade e mantém viva a memória sociobiocultural - interligando as dimensões social, biológica e cultural de um povo, associadas aos elementos da natureza. Percebe-se que o modelo de desenvolvimento econômico, em especial, a especulação imobiliária e o crescimento da Região Metropolitana de Salvador para o Litoral Norte, tem descaracterizado vilas de pescadores, determinando-as como ex-vilas, mesmo com a atividade, a rotina e a tradição da pesca artesanal presente no modo de vida dos moradores locais.
\end{abstract}

Palavras-chave: Pesca Artesanal. Pescadores - Arembepe (BA). Condiçoes sociais.

\section{Fernanda Vera Cruz Silva- \\ Meneses}

Mestra em Planejamento

Ambiental pela Universidade

Católica de Salvador - UCSAL.

Professora da Prefeitura de

Camaçari - BA.

Brasil

nandavcs@gmail.com

Patricia Carla Barbosa Pimentel

Doutora em Desenvolvimento e

Meio Ambiente pela

Universidade Estadual de Santa

Cruz - UESC. Professora do

Centro Universitário UNIFTC,

Professora da UAB da Univ.

Estado da Bahia - UNEB e

Professora do Estado da Bahia.

Brasil

patriciacbp@gmail.com

\section{Marcelo Cesar Lima Peres}

Doutor em Ecologia pela

Universidade Federal da Bahia -

UFBA. Professor da Universidade

Católica de Salvador - UCSAL.

Brasil

marcelo.peres@pro.ucsal.br

\section{Para citar este artigo:}

SILVA-MENESES, Fernanda Vera Cruz; PIMENTEL, Patricia Carla Barbosa; PERES, Marcelo Cesar Lima. A reiteração do assalto ao paraíso: pesca, pescadores e marisqueiras de Arembepe, Bahia. Revista PerCursos, Florianópolis, v. 20, n.42, p. 225 - 252, jan./abr. 2019. 


\title{
The reiteration of assault on paradise: fishing, fishermen and shellfisheries of Arembepe, Bahia
}

\begin{abstract}
This article aims to analyze the fishing tradition in the fishing community of Arempebe (BA). The investigative gaze was directed on the book Assault on Paradise, by the American anthropologist Conrad Kottak, who in the 1960 s adopted such place as his field of study. This study is an ethnobiological research and adopts a qualitative approach. A total of 31 fishermen and shellfisheries were interviewed; they were 40 years old or above that age, and all linked to the Z-14 fishing community. In the fishing community of Arembepe, the fishing method is handmade and the tradition has been maintained throughout generations. The preservation of cultural traits is present in the community and keeps the socio and biocultural memory alive - interlinking the social, biological and cultural dimensions of the local people, associated with the elements of nature. It is easily noticeable that the model of economic development, particularly the real estate speculation and the growth of the Metropolitan Region of Salvador to the North Coast, has deprived fisherfolk villages, reducing them to "ex-villages", even with the activities, routine and the tradition of the artisanal fishing still present in the lifestyle of local residents.
\end{abstract}

Keywords: Artisanal Fishing. Fisherman - Arembepe (BA). Social Condition. 


\section{Introdução}

A atividade pesqueira sempre foi uma prática de comunidades que habitam áreas litorâneas e estuarinas (ALVES et al., 2017). O que se sabe sobre os mares e os rios deve-se ao acúmulo de informações que surgiram quando o homem iniciou sua vida na terra, sua observação dos mares, dos cursos d'água e dos seres vivos que neles habitavam. Assim, o conhecimento por parte dos pescadores e marisqueiras é resultante das atividades de pesca e navegação (DIEGUES, 1995).

Em um trabalho de síntese histórica sobre socioantropologia das comunidades de pescadores, Diegues (1999) relata que a pesca constituiu uma importante atividade para fins alimentares (voltada para peixes, moluscos, crustáceos), mesmo antes da chegada dos portugueses ao Brasil. Sítios arqueológicos registram a presença de sambaquis ao longo do litoral brasileiro, corroborando a relevância da atividade pesqueira. Posey (1986, p. 21) constata que "as populações indígenas são as que melhor conhecem a pesca natural por tê-la explorado durante milênios".

Na contemporaneidade, trabalhos de antropologia que enfocam comunidades de pescadores são publicados em diversas regiões do mundo, a exemplo de estudos referidos e identificados por Diegues:

[...] em 1960 e 1966 publicaram-se trabalhos sobre comunidades de pescadores no sul da Tailândia. Entre 1967 e 1970, Formam estudou os pescadores de jangada do nordeste brasileiro, o mesmo acontecendo com Kottak (1966) ao estudar comunidades de pescadores da Bahia (Brasil). No início da década de 70, Breton publicou seus primeiros trabalhos sobre pescadores do Canadá e, no Brasil, Mourão $(1967,1971)$ e Diegues (1973) estudaram os pescadores do litoral sul de São Paulo. (DIEGUES, 1995, p. 16)

Assault on Paradise, ou "assalto ao paraíso", como se intitula a obra de Kottak, de 1962, é um estudo antropológico sobre a então vila de pescadores de Arembepe, em uma escala temporal - "entre os anos de 1962 a 1990" (KOTTAK, 1999, p. 3), sobre as mudanças sociais sofridas localmente. 
Revela-se a importância dada por antropólogos a investigações em comunidades de pescadores e verifica-se que a pesca artesanal se faz presente no litoral brasileiro. Trata-se de uma atividade extrativista do ecossistema aquático e divide espaço com outras atividades produtivas, como, por exemplo, a maricultura e atividades relacionadas ao turismo ecológico (CLAUZET; RAMIRES; BEGOSSI, 2007).

Teramoto (2014) ressalta que práticas ligadas ao turismo ecológico, como a pesca esportiva, têm o número de participantes interessados e elevado anualmente e a expansão dessa atividade preocupa pescadores, pesquisadores e comunidades locais por causa da pressão sobre os elementos naturais dispostos nas zonas costeiras.

Percebe-se, associado ao turismo, um esforço para a descaracterização da cultura pesqueira em grande parte do litoral brasileiro, a exemplo na Baixada Santista, onde se verifica, a partir do estudo de Carlos Romani, a redução, mas não extinção do modo de vida e cultura ligadas às atividades de pesca e mariscagem, ou seja, o comprometimento da cultura pesqueira, impulsionada pela demanda econômica, como a turística e portuária (ROMANI, 2010).

Para diversas comunidades, a pesca artesanal é de importância significativa, pois constitui a principal fonte de renda de inúmeras famílias. É mais do que uma atividade econômica, pois se revela como um modo de vida, garantindo a alimentação e o sustento (renda) (FREITAS; NOGUEIRA; MOURA, 2015).

Pena e Minayo Gomez descrevem a organização de pescadores artesanais:

Os pescadores artesanais se organizam por meio de colônias, associações e movimentos religiosos, mas não têm forma política assemelhada às categorias assalariadas e aos respectivos sindicatos. Todavia, cresce o movimento nacional de defesa dos territórios de pesca e dos povos tradicionais, uma vertente dos movimentos ambientalistas, que conduzem a defesa simultânea do lugar de trabalho e da preservação ambiental. (PENA; MINAYO GOMEZ, 2014, p. 4694) 
Dessa maneira, o elo de pertencimento de pescadores e marisqueiras ${ }^{1}$ com os recursos aquáticos possibilita a criação de formas de se relacionar com a natureza e manejo específicos, fruto da compreensão do hábito animal e observação intensiva e diária da natureza. Revela-se, desse modo, que pertencer ao mar, ao rio é, acima de tudo, conhecê-los em profundidade; é uma compreensão moldada através do convívio diário com o ambiente. Compreender os saberes das águas é fundamental para ser pescador e marisqueira (RAMALHO, 2004).

Verifica-se que o estado da Bahia é moldado com uma grande extensão de zonas litorâneas-costeiras; o traço cultural da arte da pesca é forte e auxilia na formação da identidade do povo baiano. Saberes tradicionais acumulados e passados de geração a geração constituem uma parte importante da cultura para a conservação do modo de vida peculiar e, em se tratando da atividade de pesca, sustentam uma relação próxima de respeito entre o homem e os ambientes aquáticos (MONTEIRO, 2014).

$\mathrm{Na}$ atualidade, Arembepe possui uma das praias mais famosas da costa norte da Bahia, destacando-se pela sua beleza e atributos históricos e, por isso, recebe ainda grande número de turistas anualmente. A localidade conta com uma larga extensão de faixa litorânea e é um lugar bastante frequentado por pescadores que residem na localidade e na região de Camaçari (PRAIAS-360², 2018).

Diante do contexto apresentado, tem-se como objetivo propor uma análise da tradição da pesca, a partir de um olhar investigativo para a comunidade pesqueira de Arempebe (BA).

\section{Área de estudo: Geografia e História}

Arembepe está localizada às margens da rodovia BA-099, conhecida por Estrada do Coco e está inserida na APA - Rio Capivara, criada pelo Decreto Estadual n. 2.219, de 14 de junho de 1993. A APA limita-se ao Norte pelo rio Jacuípe, a leste pelo Oceano Atlântico,

\footnotetext{
1 Pescadores artesanais são homens e mulheres que se dedicam à pesca. Embora seja mais comum marisqueiras pescarem no continente, esse tipo de prática não é frequente em ambientes marinhos devido a dificuldades relativas ao tempo embarcadas e às condições sanitárias inexistentes nas embarcações.
} 
a oeste pela rodovia BA-099 e ao sul pela indústria Millenium, Km 20 da referida rodovia (Figura 1).

Figura 1 - Mapa de Localização da APA Rio Capivara

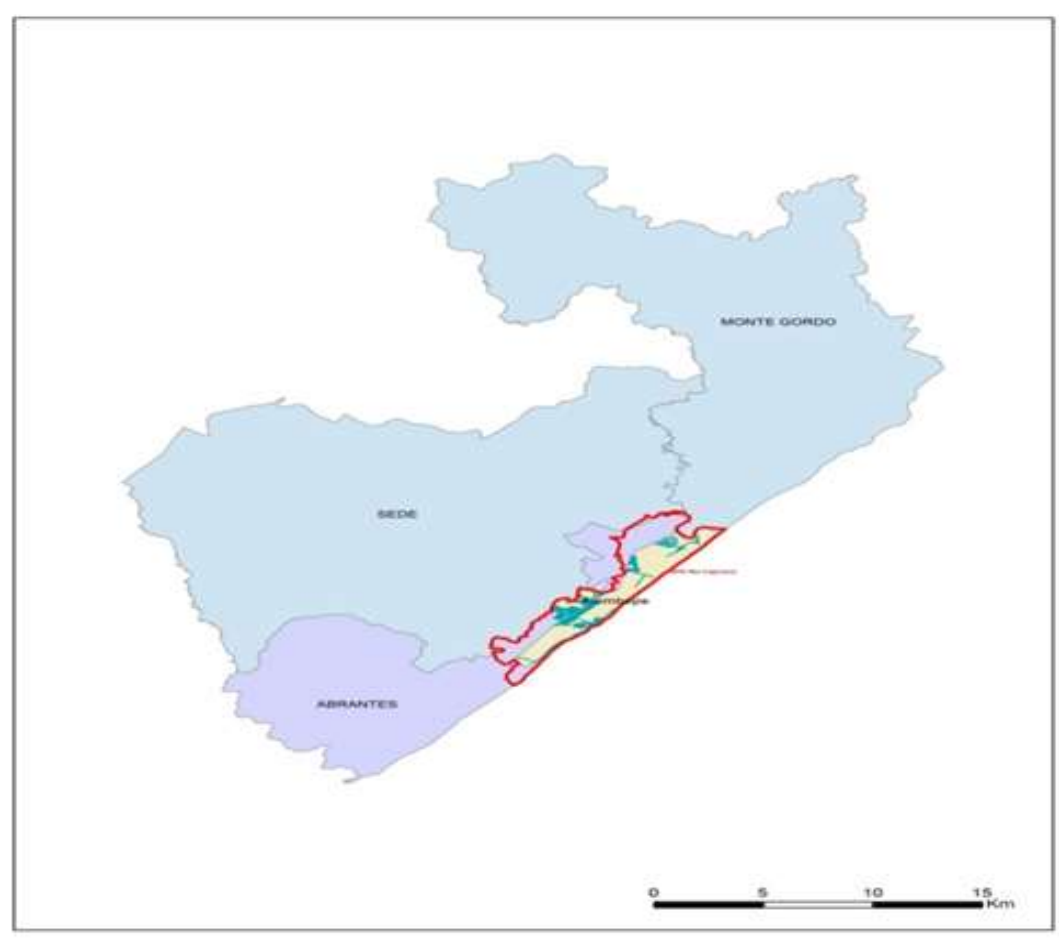

Fonte: P.M.C/ SEDUR/ CPL, 2016.

Em tupi guarani, Arembepe significa "aquilo que nos envolve"; a vila está associada, comumente, à aldeia que, nos anos 1970, recebeu o movimento Hippie de paz e amor, ficando famosa em todo o mundo, inclusive pela presença de personalidades como Janis Joplin, Mick Jagger e Roman Polanski, que passaram pela aldeia. É um lugar singular, de rica natureza e fascinante, situado entre lagoas e o oceano (KOTTAK, 1999; PROJETO TAMAR, 2018).

Em pesquisa ao acervo de documentos do Arquivo Público do Estado da Bahia sobre a área de estudo, foi encontrado documento histórico datado de 27 de junho 1887; trata-se de um Ofício enviado pela Câmara de Abrantes ao Presidente da Província da Bahia. No corpo desse documento há dados relativos à descrição do município quanto à topografia, população (descrita como mamelucos, escravos e índios em extinção), 
aspectos gerais como mar e portos (cita o porto de Arembepe), rios e lagoas (várias áreas alagadas, fazendo, inclusive, referência às lagoas de Arembepe), salubridade, minerais, frutas e animais silvestres, inventário de espécies faunísticas (do rio e mar, citando o olho de boi, camarão, traíra, espécies de peixes conhecidos por esses nomes até os dias atuais).

Observa-se, dentro da perspectiva histórica, com base na descrição presente no documento referido que, Arembepe é território de comunidade e povos tradicionais, ratificando a presença e a ancestralidade dos conhecimentos desses povos, inclusive, os pescadores e marisqueiras da localidade.

Durante a década de 60, não era fácil chegar à pequena vila de pescadores. Como não havia estrada, os carros trafegavam por areia, dunas, lagoas e lama, passando através da Vila de Abrantes e por plantações fechadas de coqueiros. Mas era uma viagem que valia a pena, dada a beleza do lugar (KOTTAK, 1999). Nessa década, 74\% dos homens da localidade viviam diretamente da pesca, enquanto as mulheres faziam redes no porto, dentre outras atividades, como lavar roupa no rio e pescar nas lagoas. Alguns homens colocavam armadilhas para a pesca do camarão nas lagoas ao norte e sul de Arembepe. Contudo, a economia local vinha do mar, através da pesca realizada com anzol e linha (KOTTAK, 1999).

Nesse mesmo período, Conrad Kottak identificou durante o desenvolvimento de seu trabalho etnográfico, o movimento cultural denominado de Chegança que acontecia no mês de julho. Naquela ocasião, os homens que pertenciam à sociedade de pescadores recontavam, na praça, como os portugueses chegaram ao Brasil. A apresentação envolvia dança formal e música em um grande evento (KOTTAK, 1999)

Entre os anos de 1965 e 1973, eram visíveis o crescimento e as diferenças encontrados em Arembepe. Os hippies estrangeiros, que se juntaram aos pescadores do rio Caratingi, construíram cabanas junto ao rio. Nota-se, assim, o crescimento do lugar por nascimentos e imigrações. Em 1964, havia 159 casas e 730 pessoas. Em 1973, já havia 340 casas e 1200 residentes (KOTTAK, 1999). A partir de 1991, Arembepe já contava com serviço de eletricidade regular e havia ruas pavimentadas e já nessa época, se parecia com 
uma pequena cidade com a expansão ao norte. Kottak identifica vários aspectos da modernização, como a implantação de diversas escolas particulares, a economia local mais baseada no turismo do que na pesca, passando a ser um destino ecoturístico (KOTTAK, 1999).

Em 1992, recebeu a base do projeto TAMAR, dedicado à preservação de diversas espécies de tartarugas marinhas e a WWF (World Wildlife Fund) também trabalhou na base do Tamar. Nesse mesmo período, a indústria Tibrás - Titânio do Brasil (atual Cristal) empregava esforços para melhorar sua imagem ambiental (KOTTAK, 1999). Por fim, Kottak (1999) afirma que várias culturas locais são vítimas de forças externas, sobretudo do modelo de desenvolvimento econômico capitalista ou do poder político. A percepção de Kottak revela que culturas humanas tendem a desaparecer quando tais poderes se tornam presentes em comunidades tradicionais.

No que se refere à cultura, a área de estudo apresenta traços marcantes descritos no Plano Diretor de Desenvolvimento Urbano - PDDU - plano municipal - que dispõe sobre a presença de pescadores artesanais, incentivos e normatização, bem como de atividades culturais, como a Primeira Chegança Feminina e a Chegança de Mouros de Arembepe. A Chegança de Mouros de Arembepe existe há mais de 60 anos e é uma tradição transmitida entre várias gerações. Ela é composta por 30 integrantes do sexo masculino e a apresentação narra, através da música e da dança, uma luta em alto-mar entre Mouros e Cristãos. No entanto, a Chegança feminina, fundada em setembro de 2002, nasceu com a proposta de fortalecimento dos Mouros de Arembepe. A Chegança feminina narra, assim como a masculina, através do canto e da dança coletiva, uma luta em alto-mar entre os Mouros e Cristãos. Suas vestes remetem a uniformes de marinheiros (REVISTA DO FESTIVAL, 2016).

\section{Os dados da pesquisa: metodologia}

A coleta de dados ocorreu por meio de entrevista semiestruturada, com perguntas abertas e fechadas, no período de março a junho de 2017. Categorias apriorísticas foram estabelecidas, inicialmente, no instrumento de pesquisa a partir dos 
interesses de pesquisa (CAMPOS, 2004): 1. Dados de identificação pessoal e social; 2. Cultura/Método/Tradição.

Os indivíduos entrevistados foram pescadores artesanais (pescadores e marisqueiras), vinculados à colônia Z-14 (compreende pescadores artesanais de Busca Vida a Barra de Pojuca e os de Camaçari-Sede). A colônia de pesca tem 1.100 (mil e cem) pescadores registrados entre ativos e inativos, sendo o número de pescadores artesanais de Arembepe de 72 indivíduos.

O critério de inclusão e exclusão dos participantes obedeceu ao seguinte pressuposto: aqueles que residiam e praticavam a pesca partindo de Arembepe e possuíam idade igual e superior a 40 anos. O fator experiência aqui é justificado a partir de Begossi:

[...] a idade é uma variável que influencia no grau de conhecimento sobre os pesqueiros, o que confirma a expectativa sobre a importância de incluir, na amostra, pescadores experientes (considerando que há maior experiência entre os mais idosos, que pescam há mais tempo que os mais novos). (BEGOSSI, 2004, p. 244)

Nesse mesmo entendimento, Torres-Avilez et al. (2014) têm considerado que pessoas com mais idade e que estão há mais tempo lidando com os recursos ofertados pela natureza detêm mais conhecimentos do que os jovens.

Portanto, o universo amostral foi de $\mathrm{n}=31$ pescadores artesanais (pescadores e marisqueiras), sendo entrevistados 20 indivíduos do gênero masculino e 11 do gênero feminino. A aplicação da entrevista junto aos pescadores aconteceu nos arredores do porto e de peixarias, auxiliada por informante para a identificação dos pescadores. Em se tratando das marisqueiras, a entrevista foi aplicada com visitas às residências das mesmas, após contato prévio.

A duração das entrevistas foi em média de 30 a 40 minutos; algumas foram gravadas, mediante permissão do entrevistado, e todas foram registradas no próprio formulário da entrevista. Durante as transcrições das falas manteve-se a própria 
linguagem utilizada pelos entrevistados, identificados por letra e número, sendo P1 para o pescador e M1 para a marisqueira, e assim sucessivamente.

Antecedendo cada entrevista, foi apresentado e lido o Termo de Consentimento Livre e Esclarecido (TCLE), e uma cópia desse termo foi deixada na colônia de pescadores. A pesquisa foi submetida ao Comitê de Ética em Pesquisa da Universidade Católica do Salvador.

Utilizou-se o método da análise de conteúdo, especificamente a análise de conteúdo temática (BARDIN, 1977). A análise de conteúdo, segundo Campos, é (2004, p. 611) "compreendida como um conjunto de técnicas de pesquisa cujo objetivo é a busca do sentido ou dos sentidos de um documento." Para Cavalcante, Calixto e Pinheiro (2014, p. 14), “[...] a análise de conteúdo compreende técnicas de pesquisa que permitem, de forma sistemática, a descrição das mensagens e das atitudes atreladas ao contexto da enunciação, bem como as inferências sobre os dados coletados".

A etapa de desdobramento operacional obedeceu a aspectos descritos por Minayo (1994, p. 68): “cronologicamente, a análise de conteúdo pode abranger as seguintes fases: pré-análise, exploração do material, tratamento dos resultados obtidos e interpretação". Durante a análise, foi realizada a leitura flutuante e a interpretação do material, por meio da observação, compreensão dos significados e percepções das falas registradas (CAVALCANTE; CALIXTO; PINHEIRO, 2014). Além disso, surgiram, com a análise dos dados, categorias temáticas posteriores, ou seja, subtemas não apriorísticos, categorias que surgiram totalmente do contexto das respostas dos sujeitos envolvidos na pesquisa (CAMPOS, 2004).

Os dados coletados foram categorizados e tabulados por temática em planilha Microsoft Excel. Essas categorias foram estabelecidas a partir do roteiro da entrevista semiestruturada - dados de identificação pessoal e social e cultura/método/tradição/ e organizados em subtemas que surgiram posteriormente. Esses dados foram analisados qualitativamente e as categorias temáticas interpretativas emergiram do contexto das respostas, da intensa leitura do material analisado e da fundamentação proveniente do campo teórico (CAMPOS, 2004). 


\section{Resultados e discussões}

\section{- A atividade pesqueira e a localização de pontos de pesca}

Na comunidade pesqueira de Arembepe, a pesca é artesanal e a tradição mantémse ao longo das gerações. A pesca ocorre tanto no ambiente marinho como no ambiente lacustre (lagoas, brejos, rios - zonas úmidas próprias do ecossistema de restinga). $\mathrm{Na}$ realização da pesca artesanal, utilizam-se embarcações de médio porte feitas de madeira. Além das embarcações, os apetrechos utilizados na prática pesqueira em Arembepe são: anzol, náilon/linha, arco (para a linha não embaraçar), faca, facão (corte de isca), iscas naturais e mortas, aço, boia e anzol, rede, cofo, jereré para camarão, jereré para siri, calão, tresmalhos.

Para uso dos apetrechos de pesca, dentro das embarcações, não existem regras específicas, ou seja, todos os utilizam. Do mesmo modo, entre as marisqueiras, é comum o uso coletivo dos objetos de pescaria. Ramalho (2004, p. 68), em pesquisa realizada em comunidade marítima e outra estuarina no estado de Pernambuco, afirma que o uso de apetrechos (redes, calão, chumbada) é baseado na relação de parentesco, na amizade. Até o uso de barcos, muitas vezes de propriedade privada, é feito na base da parceria. Nota-se o comportamento de cooperação e solidariedade no uso dos equipamentos e dos apetrechos essenciais à pesca. Ressalta-se que muitos desses equipamentos e apetrechos são confeccionados manualmente pelos próprios pescadores artesanais, o que denota que o conhecimento tradicional é empregado em técnicas de elaboração de redes, tarrafas, na peculiaridade observada no entrelaçamento das linhas de náilon e nos recursos vegetais utilizados na fabricação do calão. Alves et al. (2017) corroboram que na comunidade pesqueira de Brejo Grande/SE, os apetrechos de pesca são comumente produzidos pelos próprios pescadores.

No que diz respeito à organização local dos entrevistados, todos estão vinculados à colônia de pesca Z-14 (Figura 2). Fora da entidade que os representa, quem orienta os tripulantes (cerca de mais ou menos quatro pescadores) são os mestres de embarcação: eles realizam o planejamento da atividade pesqueira no mar. É atribuída ao mestre, conforme Oliveira et al. (2016), a responsabilidade sobre o planejamento de navegação. 
Além disso, ele desloca o barco para o pesqueiro onde ocorrerá a atividade de pesca. Cabe aos pescadores tripulantes a operação e uso dos apetrechos de pesca, disponíveis para captura do peixe, bem como a conservação do pescado em caixas de isopor com gelo, previamente introduzidas na embarcação por uma equipe de apoio na praia.

Figura 2 - Sistema de organização local de pescadores e marisqueiras de Arembepe (CamaçariBahia)



Fonte: Elaboração dos autores.

A realização da pesca por mulheres ocorre comumente nas áreas úmidas, brejos, lagoas e riachos na localidade; realizam a pesca na praia, embora poucas saiam embarcadas e, quando saem, realizam a atividade por algumas horas e retornam ao final do dia. Isso porque as embarcações de médio porte de madeira, comumente utilizadas para a pesca oceânica, apresentam restrições estruturais; como exemplo, não possuem banheiro, não havendo local reservado para as necessidades fisiológicas e higiene feminina. Observações de Oliveira et al. (2016), na Reserva de Desenvolvimento Sustentável Estadual Ponta do Tubarão, Rio Grande do Norte, se assemelham ao encontrado em Arembepe no que se refere ao desenvolvimento da pesca. Nessa 
localidade, não há presença de mulheres em embarcações que saem ao mar, uma vez que a estrutura do barco não oferece privacidade.

Verifica-se, portanto, que no sistema de pesca das marisqueiras não há entre elas uma organização hierárquica. A relação é horizontal, de cooperação e amizade; normalmente saem em duplas ou em grupos para a pescaria e desenvolve-se a pesca baseada no modo de vida solidário. O peixe e o marisco são destinados para o consumo do núcleo familiar, venda direta e em pequenas quantidades. Burda e Schiavetti (2008) observaram, em estudo realizado em Itacaré (BA), que a pesca realizada por mulheres está relacionada à mariscagem.

No entanto para o desenvolvimento da atividade por homens faz-se necessária à implementação de um planejamento, pois se trata de um volume maior de pescado a ser capturado; consequentemente, com mais tempo dedicado à pesca, podem ficar embarcados em média de três a quatro dias. Toda essa dinâmica abastece as peixarias e constitui elemento de sustento financeiro para o pescador artesanal. Verifica-se que os barcos de pesca, em muitos casos, não são de sua propriedade. Oliveira et al. (2016) identificaram em Ponta do Tubarão ( $R N)$, que os proprietários dos barcos delegam mestres de sua confiança para a operação da embarcação e, em Arembepe, tal fato é comum muito embora haja pescadores que possuam seu próprio barco.

De uma maneira geral, Pena e Minayo Gomez (2014) consideram que essa atividade de produção secular está fundada em uma dinâmica local peculiar, o que garante uma produção de pescado durável. Os trabalhos e tarefas são bem divididos, apresentando um modo de solidariedade e cooperação que contém objetivos comerciais e de sobrevivência.

No que se refere ao método de localização da área de pesca, denominado de pesqueiros, Begossi (2013) os define como cardumes de peixes, agregados em manchas, em rios e mares onde encontram o pescado. Segundo os entrevistados nessa pesquisa, pesqueiros são pontos onde é possível encontrar determinadas espécies de pescado, a depender do comportamento e habitat do peixe ou marisco que se pretende pescar. 
Embora para $65 \%$ dos pescadores entrevistados a localização do pesqueiro se dê com a utilização do recurso tecnológico como o GPS - Sistema de Posicionamento Global, técnicas seculares de etnoconhecimento espacial são utilizadas, conforme registrado pelo pescador P3: "Marcava pelas terras altas. Nunca se esquece, mas hoje usa o GPS" (PESCADOR 3, 2017).

Contudo, 35\% dos pescadores fazem uso apenas da triangulação, ou seja, seu “próprio sistema de cartografia” (SILVA, 2007, p. 28). Essa técnica emprega acidentes geográficos, a exemplo de morros, depressões no relevo da costa ou referências em solo, como torres de igreja e antenas de celulares, para a localização dos pontos de pesca. Quando a embarcação se afasta da costa é possível avistar dois pontos em terra que os pescadores previamente conhecem; localiza-se o pesqueiro, ou seja, estão sobre uma área de vida, onde há peixe (BEGOSSI, 2004), conforme PESCADOR 20(2017), PESCADOR 13(2017) e PESCADOR 7(2017), respectivamente: “Marcas de montanhas, coqueiros, torres da Millenium"; "Pelas marcas (em terra) de coqueiros, torres e morros de areia"; “Através das terras cada pesqueiro faz uma marca".

Porém, nota-se que, embora a maioria use o GPS, existem pescadores que combinam os dois métodos: utilizam o GPS e a marcação no continente, sem abandonar a tradição da triangulação para encontrar os pesqueiros, de acordo com PESCADOR 4 (2017). Há aqueles que não confiam na marcação do GPS, fato mencionado pelo pescador PESCADOR 12 (2017), pois afirmam que erram por cerca de cinco metros: "Mesmo com o GPS, observa as marcas (marcas em terra)" (PESCADOR 4, 2017); "Não confio totalmente no GPS, então uso as marcas na terra" (PESCADOR 12,2017).

O modo antigo e tradicional permanece na memória e no exercício da arte da pesca. Embora a presença do recurso tecnológico na localização dos pesqueiros seja expressiva, verifica-se que a pesca artesanal, na área de estudo, não se desarticulou da tradição secular. Portanto, nota-se um ponto de entrelace, a composição da tradição (triangulação) e da modernidade (GPS) e a confiança no saber da triangulação para a verificação da localização da área de pesca na comunidade pesqueira de Arembepe. Esse cenário, com o recurso tecnológico sendo utilizado na atividade pesqueira, requer a necessidade de um estudo comparativo com pescadores de idade menor ou igual a 39 
anos, a fim de verificar como se dá a transmissão e assimilação do saber tradicional entre os mais jovens, principalmente diante dos recursos tecnológicos disponíveis na sociedade moderna.

Ressalta-se que os pesqueiros conhecidos pelos pescadores de Arembepe recebem nomes que os identificam, possivelmente, nomes dados por pescadores ancestrais e relacionados a características geográficas avistadas da embarcação em relação ao continente. Em estudo realizado por Silva (2011) com pescadores artesanais no Rio Negro, na Amazônia brasileira, a autora refere-se à memória oral que os pescadores desenvolvem na marcação dos pontos de pesca, o que pode estar relacionado com particularidades geográficas na costa, evidenciando o domínio territorial.

Diegues (1995) esclarece que, em relação ao mar, muitos desconhecem que ele é, na verdade, um território cheio de marcas. Essas marcas, os pesqueiros, são instituídas pelos pescadores dentro de um processo relacionado à pesca marítima. Nesse sentido, Ramalho (2004) considera que o entendimento das artimanhas das águas, ou seja, o conhecimento pesqueiro, é patrimônio ancestral e é propagado através de falas, histórias contadas e até mesmo da observação dos pescadores mais antigos no exercício da pesca. A partir dessas circunstâncias é que são revelados aos mais jovens os segredos das águas e as técnicas de pescas a serem utilizadas. Pesqueiros são desvendados, a utilização da isca adequada e entendimentos de navegação são trazidos à luz, sendo revelados os meios de utilização e o mapeamento do mar dentro e fora dele.

Da mesma forma que os pescadores no mar identificam as zonas de vida, onde é possível pescar, as marisqueiras têm pontos de pesca estabelecidos, como o rio da aldeia, o rio Jacuípe e uma área de mariscagem e pesca citada e denominada "lancha". Para Silva (2007), a cartografia efetuada pelos pescadores e marisqueiras sobre o mar, rios e lagoas demonstra a territorialidade nas áreas em que eles exercem a pesca. Ataide e Martins (2000) consideram que o conhecimento tradicional espacial, chamado de etnocartografia, constitui uma ferramenta de gestão territorial, pois através do saber de comunidades acerca do território, as comunidades tradicionais estão aptas a gerir o espaço compondo estratégia de conservação biológica. Portanto, nesse contexto, tem-se 
a possibilidade de desenvolver atitudes que promovam a conservação da biodiversidade local ao somar os saberes tradicionais ao saber científico.

Verifica-se que a "lancha", antes local de pesca das marisqueiras, atualmente vem sendo ocupada por imóveis. Nota-se, contudo, através de observações em campo e nas entrelinhas das entrevistas, que a ocupação imobiliária, sem ordenamento, interfere na mariscagem local. Assim sendo, reforça-se a necessária participação dos pescadores artesanais nas audiências públicas da comunidade local em planos de gestão da APA para atenuação de impactos socioambientais.

Ramires, Molina e Hanazaki (2007) chamam atenção para que planos de manejo incorporem os conhecimentos locais e as experiências empíricas, o modo de vida, a cultura local, para efetivamente exercitar a gestão participativa em discussões que envolvem a sustentabilidade ambiental, a conservação ambiental, a fim de garantir a qualidade do meio ambiente local. Magalhães, Costa Neto e Schiavetti (2011) destacam a importância da valorização do conhecimento local e a perpetuação desses saberes auxilia na conservação ambiental da biodiversidade, inclusive considerando o Litoral Norte do estado da Bahia.

\section{- A continuação da tradição pesqueira e a cultura na localidade}

Foi identificado que a continuação da tradição da pesca ocorre por meio da comunicação oral dos pescadores e marisqueiras mais velhos para com os mais novos e os que se aproximam da atividade por motivos diversos. Santana (2014) revela, em pesquisa sobre a percepção ambiental de marisqueiras em Pirambu/SE, que, para exercer a atividade de pescador profissional, todos passam por um curso ofertado pela Capitania dos Portos. Ao contrário do que ocorre com os pescadores de Pirambu, em Arembepe o ensino da arte da pesca é apoiado na tradição ancestral, na verbalização do saber em prática diária e nas observações.

Nesse contexto, ao questionar os pescadores e marisqueiras entrevistados sobre quem foi responsável pelos ensinamentos da arte da pesca, obteve-se o seguinte resultado: $45,2 \%$ das respostas fazem menção à figura paterna e/ou materna como 
responsável pela transferência do conhecimento. Ao se justificarem diante da pergunta, alguns revelaram que os pais eram ou são proprietários de embarcação; pescadores e marisqueiras mais experientes da comunidade e sem vínculo familiar com os participantes da pesquisa compõem 25,9\% das respostas; aqueles que aprenderam a pescar sozinhos, motivados pela curiosidade e dom, somam 16,1\%; avós representam 6,4\%; e tios, 6,4\% citaram esses últimos como transmissores do conhecimento tradicional para os pescadores e marisqueiras da localidade.

Ramalho (2004) e Ramires, Molina e Hanazaki (2007) corroboram em seus estudos que o conhecimento sobre a pesca em geral é transmitido através do convívio com os mais experientes e do exercício no cotidiano, dos mais velhos ensinando aos mais jovens, através da oralidade e da observação. Em estudo realizado por Freitas, Nogueira e Moura (2015), no baixo rio São Francisco, os pescadores artesanais aprenderam a arte da pesca por influência dos pais e, em menor proporção, da mãe. Entende-se que a responsabilidade pela transferência do conhecimento dar-se-á, nesse caso, pela relação direta entre os genitores e os descendentes diretos, levados pelos seus ancestrais que os envolviam na atividade coletiva da pesca, no sentido de ajudar no desenvolvimento do trabalho. Dessa aproximação, muitos se efetivam na atividade por diversos motivos, sendo eles: a identificação com a atividade, tradição familiar, meio de obtenção de alimento para si e família, meio de obtenção de renda, dentre outros aspectos.

Em suma, foi identificado que mesmo antes de exercerem profissionalmente a pesca, ou seja, sem registro em órgãos competentes, e sem terem alcançado a maioridade, os pescadores e marisqueiras de Arembepe já estavam de alguma forma envolvidos com a pesca. Conduzidos pelo pai, mãe, vizinhos, pela curiosidade e/ou pelos pescadores e marisqueiras mais experientes, foram, assim, influenciados. Em estudo semelhante realizado por Burda e Schiavetti (2008), constatou-se que pescadores nativos da localidade de Itacaré, desde pequenos, aprenderam a pescar com os pais e familiares.

O desafio no manejo e as especializações que a atividade impõe constituem um fator preponderante de aproximação dos mais jovens, uma vez que o mundo das águas carrega mistérios e desafios a serem vencidos. Para muitos, o gosto pela pesca começa a partir dessa experiência de acompanhar os mais velhos no desenvolvimento da atividade. 
Desse modo, perguntou-se aos pescadores e marisqueiras se eles ensinam o que sabem a interessados. Até o período de aplicação das entrevistas, 51,7\% afirmaram que não haviam ensinado por não terem oportunidade ou por não terem sido procurados. Entretanto, 48,3\% dos entrevistados afirmaram que já tiveram oportunidade de ensinar e que ensinam aqueles que demonstram interesse e os procuram.

Evangelista-Barreto et al. (2014, p. 468) identificaram em pescadores artesanais de São Francisco do Conde/BA que a tradição da pesca "tem sido ignorada pelos mais jovens". Nota-se que, em Arembepe, situação semelhante vem acontecendo, conforme destacam o pescador (P11) e a marisqueira (M6), ao justificarem o porquê de não ensinarem o que sabem sobre a arte da pesca: “Não. Tá ficando difícil. Ninguém quer aprender” (PESCADOR 11, 2017); “Não. Não querem mariscar, as antigas mariscam" (MARISQUEIRA 6, 2017).

Embora permaneça a tradição da pesca na localidade, as modificações sociais pelas quais a comunidade pesqueira passou e vem passando ao longo dos anos, confirmam o baixo interesse em relação à atividade pesqueira pelos mais jovens, que veem outras possibilidades de trabalho e sustento. O acesso aos centros urbanos como Camaçari-Sede, Lauro de Freitas e Salvador é facilitado por boas condições das estradas e do sistema de transporte público na localidade. Outro fator é a possibilidade de inserção no mercado de trabalho em segmentos locais de bens e serviços, associados ao turismo local, como restaurantes, lojas de artigos de praia, chalés, pousadas e hotéis, uma vez que Arembepe é um destino turístico, em virtude da Aldeia Hippie e de suas praias. Por conseguinte, Oliveira et al. (2016) afirmam que se faz necessário destacar e trabalhar, através da sensibilização, entre os mais jovens, que a pesca é uma atividade promissora dentro do ponto de vista socioeconômico.

Mas, mesmo com a ausência desse interesse pelos mais jovens, a arte da pesca é transmitida de geração a geração tendo em vista que ela é a forma mais comumente utilizada para difundir esses conhecimentos. Tal fato reforça que a pesca artesanal em Arembepe tem importante papel na economia local e para a manutenção de famílias, cenário que corrobora a perpetuação da atividade até os dias atuais. 
Os pescadores veem na atividade a possibilidade de sobrevivência e se aproximam dos que estão na ativa: "Ensino. Os mais jovens" (PESCADOR 1,2017) ; "Sai mais as sobrinhas e as amigas que não sabem, aí ensina” (MARISQUEIRA 3, 2017) ; "Ensino quando procurado, aos mais jovens, quando querem” (PESCADOR 5, 2017) ; “Já ensinei. As meninas (sobrinhas)" (MARISQUEIRA 5, 2017). Para Ramalho (2004, p. 64), “o sentido da tradição ganha contornos nítidos nas falas" que ressaltam a intenção de transmitir e difundir a arte da pesca entre os seus na comunidade.

O saber por meio da tradição, mesmo com os avanços da modernidade, é característico, pois a relação que se tem como a natureza é empírica e fortemente estabelecida pela inter-relação desenvolvida em decorrência da dependência da natureza para a execução da pesca. Esse vínculo com o ambiente natural é movido basicamente pela necessidade de sobrevivência, seja relativa ao caráter de subsistência e/ou econômico. Contudo, afirma-se que para a perpetuação da tradição, é fundamental a conservação do ambiente local.

Ao serem questionados sobre os motivos pelos quais os pescadores $\mathrm{e}$ marisqueiras aproximaram-se da pesca, foram apresentados sete motivos: o dom/gosto/curiosidade, a tradição, o sustento/sobrevivência, a amizade, a evasão escolar, o interesse financeiro, a oportunidade/não tinha o que fazer (Tabela 1).

Tabela 1 - Categorização temática dos motivos que levaram pescadores e marisqueiras, vinculados à colônia de Z-14, a praticar a pesca em Arembepe (Camaçari-Bahia)

\begin{tabular}{|c|c|c|l|}
\hline Motivação & $\begin{array}{c}\text { Repetições } \\
\text { (Pescador) }\end{array}$ & $\begin{array}{c}\text { Repetições } \\
\text { (Marisqueira) }\end{array}$ & \multicolumn{1}{|c|}{ Falas } \\
\hline Tradição & 03 & 03 & $\begin{array}{l}\text { Vem de família. Estou envolvido desde } \\
\text { pequeno. Sempre quero está no mar - P3 / } \\
\text { Desde pequeno ajudava o pai, aí se } \\
\text { interessou - P4 / A infância com os avós, os } \\
\text { vizinhos, cresceu indo para a aldeia. - M1 / É } \\
\text { de criação. Meu pai pescava e mãe } \\
\text { também. - M8 / Do sangue. De família. É do } \\
\text { rio e mar - M11. }\end{array}$ \\
\hline
\end{tabular}




\begin{tabular}{|c|c|c|c|}
\hline $\begin{array}{c}\text { Sustento/ } \\
\text { Sobrevivência }\end{array}$ & 05 & 01 & $\begin{array}{l}\text { Não tinha as coisas em casa. Aí teve que } \\
\text { jogar rede no mar para pegar minha } \\
\text { sobrevivência- }{ }^{4} \text {. }\end{array}$ \\
\hline Amizade & 01 & 02 & $\begin{array}{l}\text { Pegando amizade - P11 / Pegando amizade - } \\
\text { M11 / Influência de ver outras pessoas irem } \\
\text { mariscar. A situação era difícil, ia pegar } \\
\text { alimento - M6. }\end{array}$ \\
\hline Evasão escolar & 01 & 00 & Não deu tempo de estudar - P8 \\
\hline $\begin{array}{l}\text { Dom/ Gosto/ } \\
\text { curiosidade }\end{array}$ & 05 & 03 & $\begin{array}{l}\text { É gratificante. Se a pessoa souber } \\
\text { aproveitar... é uma profissão gratificante - } \\
\text { P5 / Desde pequeno gostava de pescar - } \\
\text { P13 / Gostava e precisava - M5 / Gostou da } \\
\text { pesca - M9 }\end{array}$ \\
\hline $\begin{array}{l}\text { Interesse } \\
\text { Financeiro }\end{array}$ & 01 & 00 & Ganhava muito dinheiro - P18 \\
\hline $\begin{array}{l}\text { Falta de opção/ } \\
\text { Não tinha o que } \\
\text { fazer }\end{array}$ & 04 & 02 & $\begin{array}{l}\text { Não tinha outra opção - P2/ Oportunidade } \\
\text { que surgiu - P10 / Era bom. Não tinha outro } \\
\text { trabalho - M2 / A maneira de viver. Não } \\
\text { tinha outra coisa para fazer - M7 }\end{array}$ \\
\hline
\end{tabular}

Fonte: Elaboração dos autores.

O modo de vida do núcleo familiar, muitas vezes, influencia os demais membros da família a tomarem esse caminho, sendo a sobrevivência o ponto-chave. 0 dom/gosto/curiosidade demonstrados como alguns dos principais motivos que levaram os pescadores artesanais a se envolverem com a pesca, tem ainda nas relações familiares fatores que os aproximam da atividade, seja pelo envolvimento desde cedo ou o fascínio que a atividade provoca; seja pelo envolvimento com os pais, as mães e os avós na pesca artesanal.

Observa-se o mecanismo tradicional como representativo na compilação da tabela acima. Nota-se a tradição marcada pela oralidade presente na transmissão da cultura da pesca e da influência dos mais antigos sobre os mais jovens, o que reafirma a característica de povos e comunidades tradicionais quanto à difusão do saber. Imbricado nessa relação, o traço de pertencimento com o mar, com o rio, se manifestam na ligação do pescador artesanal com as águas e com o ecossistema aquático de uma maneira geral.

Quando questionados se consideram importante a manutenção da tradição da pesca, os participantes da pesquisa foram contundentes em afirmar que sim. Apresentam-se, então, os porquês dos entrevistados, em quatro categorias temáticas: 
cultura/tradição, sobrevivência, fonte de alimento, preocupação com a geração futura (Tabela 2).

Tabela 2 - Justificativa temática sobre a importância da continuação da pesca artesanal no entendimento dos pescadores e marisqueiras entrevistados de Arembepe, vinculados à colônia de pesca Z-14 (Camaçari-Bahia)

\begin{tabular}{|c|l|}
\hline Justificativa & \multicolumn{1}{c|}{ Expressões } \\
\hline Cultura/Tradição & $\begin{array}{l}\text { É uma cultura - P19 / Acho. É uma profissão milenar - P20. / } \\
\text { Sim, com certeza. Já vem do passado. É antigo. Não pode acabar. - p? / } \\
\text { Os pescadores de Arembepe criaram os filhos com a pesca - M9./ Acho. É } \\
\text { Conito. Já vem de berço - P6. / } \\
\text { aprendem - P4./ } \\
\text { Acho. Para não acabar a tradição - M5./ } \\
\text { Acho. Tradição que vem de anos. Vai acabar. Tem poucos pescadores } \\
\text { aqui em Arembepe, mesmo - P11 }\end{array}$ \\
\hline $\begin{array}{c}\text { Meio de } \\
\text { Sobrevivência }\end{array}$ & $\begin{array}{l}\text { Acho. Sobrevivência - P16. / Sim. Único sustento da família- M11./ Acho. } \\
\text { As minhas "coisas" veio da mariscagem - M4. . Claro. Se acabar acaba } \\
\text { tudo-P18. }\end{array}$ \\
\hline $\begin{array}{c}\text { Fonte de } \\
\text { Alimentação }\end{array}$ & $\begin{array}{l}\text { Acho. Vai comer peixe de onde? Se não pescar... a pescaria é melhor que } \\
\text { tem... - P9. }\end{array}$ \\
\hline $\begin{array}{c}\text { Preocupação com } \\
\text { a geração futura }\end{array}$ & $\begin{array}{l}\text { É uma atividade que não pode se acabar porque tem filhos e bisnetos - } \\
\text { P12. }\end{array}$ \\
\hline
\end{tabular}

Fonte: Elaboração dos autores.

Ao lado de cada classificação temática, tem-se a expressão do pescador e da marisqueira, justificando a relevância da tradição na localidade. No entanto, há expressões, dentro desse mesmo contexto, que denotam preocupação sobre as consequências, na percepção do pescador artesanal, quanto ao declínio da tradição, quando emergiu a quarta categoria temática: preocupação com a geração futura.

Os pescadores possuem essa consciência e sentem-se orgulhosos da atividade que desempenham pois são movidos pelos desafios impostos pela natureza. Em 
contrapartida, o retorno que o meio ambiente dá em recursos faunísticos é certo, havendo a sua conservação.

A manutenção da tradição permanece não apenas como garantia de trabalho para os pescadores e marisqueiras, mas também como indicador de equilíbrio ambiental, de um ecossistema resiliente, que oferta o pescado. Por outro lado, o contínuo aprendizado favorece o surgimento de outros saberes, oriundos da observação empírica, exercida pelos pescadores e marisqueiras por meio da tradição. Por certo, é uma atividade exaustiva, que requer paciência, e interfere na escolaridade dos pescadores artesanais, mas, ainda assim, atrai filhos e netos e até mesmo outros indivíduos sem vínculo familiar para dar continuidade da tradição.

Tradição e cultura coexistem em comunidade tradicionais. Ramires, Molina, Hanazaki (2007) afirmam que o conhecimento local de comunidades de ambiente costeiro marinho é vasto e apresenta êxito na tarefa da pesca, além de fazer parte de seus traços culturais. Por conseguinte, a localidade de Arembepe apresenta manifestações culturais próprias e históricas. A Chegança e o samba de roda são expressões presentes na comunidade até os dias atuais.

Dos pescadores e marisqueiras entrevistados, $22,5 \%$ participam da atividade cultural da Chegança. Os entrevistados consideram importante essa atividade, conforme apresentado nos relatos registrados a seguir: "É uma tradição local importante" (PESCADOR 3, 2017 e participante da Chegança) ; "Gosto. Desde criança ia com pai, ele fazia o mouro" (MARISQUEIRA 6, 2017 e participante da Chegança).

Por outro lado, a maioria dos entrevistados, 77,5\% dos pescadores artesanais, não participa da Chegança porque não se interessa ou, mesmo achando uma atividade cultural linda, não apresenta habilidades: "Não tenho gingado" (PESCADOR 7, 2017). ; "Ia participar, mas não quis. Acho lindo" (MARISQUEIRA 2, 2017).

$\mathrm{Na}$ tradição da pesca, está presente o elemento biológico (o pescado) que influencia o modo de vida local. A cultura dos antigos permanece na memória, na história e no costume local, apesar dos processos de mudanças vivenciados pelas sociedades contemporâneas. A preservação dos traços culturais fortalece a comunidade e mantém 
viva e presente a memória sociobiocultural, que é o entrelaçamento de um modo social de vida peculiar associado ao universo pesqueiro e ao ecossistema aquático, imbricados pela relação ecológica e cultural da comunidade.

Nesse contexto, as escolas da comunidade necessitam conhecer e se apropriar dos saberes locais do entorno para o seu fortalecimento (ANDREOLI; CAMPOS, 2016) e, para a manutenção e conservação da natureza, uma vez que a tradição da pesca está diretamente conectada ao contexto ambiental.

\section{Considerações finais}

Analisando a tradição da pesca na localidade estudada, observou-se que a tradição, a memória e as manifestações da cultura local têm resistido às mudanças sociais ocorridas ao longo do tempo. A localidade preserva o modo de vida tradicional com referência à arte da pesca. Retratado na transmissão oral do conhecimento (dos mais velhos aos mais novos), no modo social de cooperação e solidariedade, nos artefatos de pesca com baixa tecnologia e a identificação de novas tecnologias sendo utilizadas no exercício da pesca. A expressão cultural, especificamente o movimento cultural da Chegança, ainda se faz presente como elemento tradicional.

Percebe-se, no entanto, que a especulação imobiliária e o crescimento da Região Metropolitana de Salvador para o Litoral Norte têm descaracterizado as vilas de pescadores, determinando-as como ex-vilas de pescadores, mesmo com atividades, rotinas e tradições da pesca artesanal tão presentes no modo de vida dos locais. Portanto, o assalto ao paraíso continua ocorrendo, quando se permite que costumes modernos se sobreponham às culturas tradicionais.

Fazem-se necessárias políticas que assegurem que cultura local permaneça sendo valorizada frente a atividades econômicas que muitas vezes não reconhecem os elementos fundamentais do paraíso: a natureza - zona costeira de beleza cênica relativamente preservada, com destaque para o ecossistema restinga - impactada pela ocupação desordenada, pelo uso do solo, pela contínua pressão imobiliária - e falta de 
valorização do turismo ecológico em relação ao povo tradicional, os pescadores e marisqueiras, presentes e atuantes na localidade.

Essa reiteração do olhar sobre o paraíso assaltado se faz necessária em caráter contínuo para a conservação do etnoconhecimento e da cultura local, assim como para o monitoramento e avaliação do status da preservação dos costumes locais e da conservação do ambiente marinho costeiro.

\section{Referências}

ALVES, Neise et al. Mudanças no cotidiano das comunidades tradicionais pesqueiras de Brejo Grande - Sergipe, Brasil. Revista GeoNordeste, São Cristóvão, Ano 38, n. 1, p. 187202, jan./jun. 2017.

ANDREOLI, Vanessa; CAMPOS, Marília. Educação ambiental, currículo e desenvolvimento comunitário: possíveis diálogos a partir do olhar dos professores da ilha do mel/PR. In: REUNIÃO CIENTÍFICA REGIONAL DA ANPED, 11. Anais: Curitiba: Anped Sul, 2016, p. 1-15.

ATAIDE, Marcos; MARTINS, Ayrton. A etnocartografia como ferramenta de gestão.

Partipatory Avenues - Integrated Approaches to Participatory Development, s.l, IAPAD, s.p, jul. 2015. Disponível em: http://www.iapad.org/search_gcse/?q=ataide. Acesso em: 19 de abril de 2019 .

BARDIN, Laurence. Análise de conteúdo. Lisboa: Presses Universitaires de France, 1977.

BEGOSSI, Alpina. Áreas, pontos de pesca, pesqueiros e territórios na pesca artesanal. In: BEGOSSI, Alpina. (Org). Ecologia de pescadores da Mata Atlântica e da Amazônia. São Paulo: HUCITEC, 2004, p. 223-253.

BEGOSSI, Alpina. Áreas, pontos de pesca, pesqueiros e territórios na pesca artesanal. In: BEGOSSI, Alpina. (Org). Ecologia de pescadores da Mata Atlântica e da Amazônia. São Carlos, RiMa Editora, 2013, p. 163-187.

BURDA, Carla; SCHIAVETTI, Alexandre. A. Análise ecológica da pesca artesanal em quatro comunidades pesqueiras da Costa de Itacaré, Bahia, Brasil: Subsídios para a Gestão Territorial. Revista de Gestão Costeira Integrada, Lisboa: APRH/UNVALI, v. 8, n. 2, p. 149168, dez/ 2008. Disponível em: http://www.aprh.pt/rgci/pdf/rgci-136_Burda.pdf. Acesso em: 08 jan. 2018. 
CAMPOS, Claudinei. Método de Análise de conteúdo: ferramenta para a análise de dados qualitativos no campo da saúde. Revista Brasileira Enfermagem, Brasília, v. 57, n. 5, p. 611614, out, 2004. Disponível em: http://www.scielo.br/scielo.

php?script=sci_arttext\&pid=So034-71672004000500019\&lng=en\&nrm=iso. Acesso em: 18 abr. 2019.

CAVALCANTE, Ricardo; CALIXTO, Pedro; PINHEIRO, Marta. Análise de conteúdo: considerações gerais, relações com a pergunta de pesquisa, possibilidades e limitações do método. Inf. \& Soc., João Pessoa, v.24, n.1, p. 13-18, jan./abr.2014.

CLAUZET, Mariana; RAMIRES, Milena; BEGOSSI, Alpina. Etnoictiologia dos pescadores artesanais da praia de Guaibim, Valença, BA, Brasil. Neotropical biology and conservation, La Rioja (España), v.2, n. 3, p. 136-154, set/ dec. 2007.

DIÁRIO OFICIAL DO ESTADO. Decreto n²219, de 14 de junho de 1993. Dispõe sobre Criação da Área de Proteção Ambiental do Rio Capivara, no Município de Camaçari, e dá outras providências. Disponível em: https://governo-

ba.jusbrasil.com.br/legislacao/83216/decreto-2219-93. Acesso em: 29 out 2016.

DIÁRIO OFICIAL DO MUNICÍPIO. Lei n 866 , de 11 de janeiro de 2008. Dispõe sobre o Plano Diretor de Desenvolvimento Urbano do Município de Camaçari e dá outras providências. Disponível em http://arquivos.camacari.ba.gov.br/compras/Anexo\%20l\%20-\%20PDDU.pdf. Acesso em: 20 abril 2019.

DIEGUES, Antonio. Biodiversidade e comunidades tradicionais no Brasil. São Paulo: NUPAUB -USP; PROBIO-MMA; CNPq, 1999.

DIEGUES, Antonio. Povos e mares: leitura sócio-antropologica marítima. São Paulo: NUPAUB, 1995.

EVANGELISTA-BARRETO, Norma et al. Indicadores socioeconômicos e percepção ambiental de pescadores em São Francisco do Conde, Bahia. Bol. Inst. Pesca, São Paulo, v.40, n. 3, p.459-470, 2014.

FREITAS, Luanna; NOGUEIRA, Eliane; MOURA, Geraldo. A pesca artesanal no cânion do rio São Francisco: modo de vida, desafios e percepções. A pesca artesanal no Baixo São Francisco: atores, recursos, conflitos. In: NOGUEIRA, Eliane.; SÁ, Maria de Fátima (Orgs.). A pesca artesanal no baixo São Francisco: atores, recursos, conflitos. Petrolina, PE: SABEH, 2015, p. 45-103.

KOTTAK, Conrad. Assault on Paradise: social change in a brazilian village. USA: McGrawHill, 1999. 
MAGALHÃES, Henrique; COSTA NETO, Eraldo; SCHIAVETTI, Alexandre. Saberes pesqueiros relacionados a coleta de siris e caranguejos (dacapoda Brachyra) no município de Conde, estado da Bahia. Biota Neotropica, Campinas, v. 11, n. 12, p. 45-54, jun. 2011.

MARISQUEIRA 2. Depoimento da Marisqueira número 2. [Entrevista cedida a] Fernanda Vera Cruz Silva Meneses. Camaçari, mar. 2017. Informação oral.

MARISQUEIRA 3. Depoimento da Marisqueira número 3. [Entrevista cedida a] Fernanda Vera Cruz Silva Meneses. Camaçari, mar. 2017. Informação oral.

MARISQUEIRA 5. Depoimento da Marisqueira número 5. [Entrevista cedida a] Fernanda Vera Cruz Silva Meneses. Camaçari, abr. 2017. Informação oral.

MARISQUEIRA 6. Depoimento da Marisqueira número 6. [Entrevista cedida a] Fernanda Vera Cruz Silva Meneses. Camaçari, abr. 2017. Informação oral.

MEIRELES, Melise; MEIRELES, Vitor; BARROS, Roseli. Características da pesca artesanal realizada na comunidade Passarinho/Ilha das Canárias/MA. Gaia Scientia, Paraíba, v. 11, p. 12-26, 2017.

MINAYO, Maria. (Org.). et al. Pesquisa social: teoria, método e criatividade. Petrópolis, RJ: Vozes, 2 edição, 1994.

MONTEIRO, Igor. Modelagem etnoecológica do território da pesca artesanal em Ilha de Maré, Salvador-BA. 2014. 100 f. Dissertação (Mestrado em Modelagem e Ciências da Terra e do Ambiente) - Universidade Estadual de Feira de Santana, 2014.

OLIVEIRA, Jônnata et al. Caracterização da pesca e percepção de pescadores artesanais em uma Reserva de Desenvolvimento Sustentável no Nordeste brasileiro. Natureza on line, Espírito Santo, v. 14, n. 1, p. 48-54, jan-jul. 2016.

PENA, Paulo; MINAYO GOMEZ, Carlos. Saúde dos pescadores artesanais e desafios para a Vigilância em Saúde do Trabalhador. Ciência \& Saúde Coletiva, Rio de Janeiro, v. 19, n. 12, p. 4689-4698, set. 2014 .

PESCADOR 1. Depoimento de Pescador número 1. [Entrevista cedida a] Fernanda Vera Cruz Silva Meneses. Camaçari, mar. 2017. Informação oral.

PESCADOR 3. Depoimento de Pescador número 3. [Entrevista cedida a] Fernanda Vera Cruz Silva Meneses. Camaçari, mar. 2017. Informação oral.

PESCADOR 4. Depoimento de Pescador número 4. [Entrevista cedida a] Fernanda Vera Cruz Silva Meneses. Camaçari, mar. 2017. Informação oral. 
PESCADOR 5. Depoimento de Pescador número 5. [Entrevista cedida a] Fernanda Vera Cruz Silva Meneses. Camaçari, mar. 2017. Informação oral.

PESCADOR 7. Depoimento de Pescador número 7. [Entrevista cedida a] Fernanda Vera Cruz Silva Meneses. Camaçari, mar. 2017. Informação oral.

PESCADOR 11. Depoimento de Pescador número 11. [Entrevista cedida a] Fernanda Vera Cruz Silva Meneses. Camaçari, mar. 2017. Informação oral.

PESCADOR 12. Depoimento de Pescador número 12. [Entrevista cedida a] Fernanda Vera Cruz Silva Meneses. Camaçari, mar. 2017. Informação oral.

PESCADOR 13. Depoimento de Pescador número 13. [Entrevista cedida a] Fernanda Vera Cruz Silva Meneses. Camaçari, mar. 2017. Informação oral.

PESCADOR 20. Depoimento de Pescador número 20. [Entrevista cedida a] Fernanda Vera Cruz Silva Meneses. Camaçari, jun. 2017. Informação oral.

POSEY, Darrell. A. Etnobiologia: teoria e prática. 1986. Disponível em: https://pt.scribd.com/document/190787984/Posey-1986-Etnobiologia-Teoria-e-Pratica. Acesso em: 09 jan. 2018.

PRAIAS-360.Praia de Arembepe. Brasil. Disponível em: http://www.praias360.com.br/bahia/camacari/praia-de-arembepe. Acesso em: 09 jan. 2018.

PROJETO TAMAR.Arembepe-Ba. Brasil. Disponível em:

http://www.tamar.org.br/centros_visitantes.php?cod=2. Acesso em: 09 jan. 2018.

RAMALHO, Cristiano. O mundo das águas e seus laços de pertencimento. Raízes, Campina Grande, PB. v.23, n. 1 e 2, p. 62-72, jan-dez. 2004.

RAMIRES, Milena; MOLINA, Silvia; HANAZAKI, Natalia. Etnoecologia caiçara: o conhecimento dos pescadores artesanais sobre aspectos ecológicos da pesca. Revista Biotemas, Florianópolis: UFSC, v. n. 1, p. 101-103, mar. 2007.

REVISTA DO FESTIVAL, Camaçari: SECULT, 1. ed., p. 36-37, jul. 2016.

ROMANI, Carlos. Comunidades caiçaras e expansão portuária em Santos - uma análise histórica do conflito. Revista Científica Integrada, Ribeirão Preto, v.1 n.1, p. s.p, set. 2010.

SANTANA, Camila. Percepção ambiental de marisqueiras. REVISEA - Revista Sergipana de Educação Ambiental, São Cristóvão, SE, v. 1 n. 1, p. 147-166, 2014 . 
SILVA, Andrea. Entre tradições e modernidade: conhecimento ecológico local, conflitos de pesca e manejo pesqueiro no rio Negro, Brasil. Boletim do Museu Paraense Emílio Goeldi. Ciências Humanas, Belém, PA, v. 6, n. 1, p. 141-163, jan-abr. 2011.

SILVA, Christian. N. A percepção territorial-ambiental em zonas de pesca. Boletim do Museu Paraense Emílio Goeldi. Ciências Humanas, Belém, PA, v. 2, n. 3, p. 25-32, dez. 2007.

TERAMOTO, Carolina. Conflitos entre pescadores artesanais e amadores de Bertioga/SP e adjacências. São Paulo, 2014. 100f. Dissertação (Mestrado em Ciências Ambientais). Universidade de São Paulo, 2014.

TORRES-AVILEZ, Wendy et. al. Gênero e idade. In: Albuquerque, Ulysses (Org.). Introdução à etnobiologia. Recife: Nuppea, 2014, p. 163-167. 